\title{
Effects of general anesthesia with combined epidural anesthesia on inflammatory response in patients with early-stage gastric cancer undergoing tumor resection
}

\author{
WEIGANG LIU ${ }^{1 *}$, LIXIA WU ${ }^{2 *}$, MIAO ZHANG ${ }^{1}$ and LIMING ZHAO ${ }^{1}$ \\ ${ }^{1}$ Department of Anesthesiology, General Hospital of Daqing Oil Field of Heilongjiang; \\ ${ }^{2}$ Department of Anesthesiology, Daqing Longnan Hospital of Heilongjiang, Daqing, Heilongjiang 163001, P.R. China
}

Received January 15, 2018; Accepted May 17, 2018

DOI: $10.3892 /$ etm.2018.6898

\begin{abstract}
The present study aimed to investigate the effects of combined epidural and general anesthesia on gastric cancer patients undergoing tumor resection. A total of 107 patients with early-stage gastric cancer who underwent surgery between January 2014 and January 2017 were enrolled in the present study. All patients in the control group $(n=54)$ were treated with general anesthesia, while patients in the observation group $(n=53)$ were treated with combined epidural and general anesthesia. The percentages of viable $\mathrm{T}$ lymphocyte subsets and the levels of carcinoembryonic antigen in the serum were measured. Furthermore, the pro-inflammatory cytokines interleukin (IL)-1, IL-8, high-sensitivity C-reactive protein (hs-CRP) and tumor necrosis factor (TNF)- $\alpha$ were measured. Compared with those in the control group, the percentages of $\mathrm{CD}^{+}$and $\mathrm{CD}^{+} \mathrm{T}$ lymphocytes and the $\mathrm{CD} 4^{+} / \mathrm{CD}^{+}$ratio in the observation group were increased, while the population of $\mathrm{CD}^{+}$cells was decreased. Furthermore, the serum levels of the pro-inflammatory cytokines IL-1, IL-8, hs-CRP and TNF- $\alpha$ in the observation group were reduced compared with those in the control group. In addition, the incidence of nausea and vomiting, as well as post-operative agitation were lower in the observation group compared with those in the control group. In conclusion, compared with general anesthesia, combined anesthesia inhibits the inflammatory response and improves immune function in early-stage gastric cancer patients undergoing tumor resection.
\end{abstract}

Correspondence to: Dr Liming Zhao, Department of Anesthesiology, General Hospital of Daqing Oil Field of Heilongjiang, 9 Zhongkang Street, Saertu, Daqing, Heilongjiang 163001, P.R. China

E-mail: gqvillj7@yeah.net

${ }^{*}$ Contributed equally

Key words: general anesthesia, combined epidural and general anesthesia, gastric cancer, inflammatory response, immune function

\section{Introduction}

Surgical resection is the most efficient treatment strategy for patients with various types of malignancy at the early stage, including gastric cancer, and the treatment outcomes are usually satisfactory (1). Anesthesia is an unavoidable peri-operative application, and various modes of anesthesia may have different effects on post-operative recovery, occurrence of short-term adverse effects or even tumor recurrence (2). Incisions made during the surgical operations may induce inflammatory responses by interrupting the synthesis and secretion of various inflammatory cytokines. To a large extent, the severity of inflammatory responses determines treatment outcomes (3), while different modes of anesthesia may have different effects on inflammatory cytokines induced by surgical operations (4). In addition, numerous studies have indicated that various peri-operative factors may damage cellular immunity to increase cell immunosuppression so as to induce tumor metastasis and recurrence, as well as shorten the patients' survival time (5). Drugs used in anesthesia and post-operative analgesia may also affect immune function (6). Therefore, it may be hypothesized that appropriate management of anesthesia and analgesia may inhibit inflammatory responses and protect immune functions in cancer patients that underwent surgical resection (7).

In this light, the appropriate management of anesthesia and analgesia may lower the impact on immune balance and improve the patients' post-operative immune function, which in turn improves the prognosis (7). General anesthesia alone and its combination with epidural anesthesia are two commonly used anesthetic modes. The present study aimed to investigate the effects of general anesthesia alone and combined with epidural anesthesia on the inflammatory response and immune function of early-stage gastric cancer (EGC) patients who underwent tumor resection.

\section{Patients and methods}

Patients. A total of 107 patients with EGC who underwent surgery between January 2014 and January 2017 at the General Hospital of Daqing Oil Field of Heilongjiang (Daqing, China) were enrolled in the present study. All patients were preliminary diagnosed by pathological examinations. EGC was defined as a 
malignant tumor confined to the submucosa and mucosa regardless of the absence and presence of lymph node metastasis (LNM) according to the classification of the Japanese Gastric Cancer Association (8). Inclusion criteria: i) Patients with EGC; ii) Patients diagnosed and treated for the first time; iii) Patients completed the whole treatment procedure in the stated hospital hospital; iv) Patients willing to participate. Exclusion criteria: i) Patients with other types of malignancies; ii) Patients received treatment prior to admission; iii) Patients allergic to drugs used in the study. The patients included 72 males and 35 females, and the age ranged from 27 to 75 years, with an average age of $49 \pm 12.4$ years. All patients received endoscopic submucosal dissection according to the methods described by Abe et al (9).

Grouping and anesthetic methods. The 107 patients were randomly divided into a control group $(n=53)$ and an observation group $(n=54)$ to receive different types of anesthesia. Patients in the control group received tracheal intubation and general anesthesia. Infusion of propofol (3-4 $\mu \mathrm{g} / \mathrm{ml}$; Claris Injectables Ltd., Ahmedabad, India) using a target-controlled micropump was performed to induce anesthesia. A single injection of fentanyl $(2-4 \mu \mathrm{g} / \mathrm{kg})$ and cisatracurium $(0.02 \mathrm{mg} / \mathrm{kg}$; both Yichang Renfu Pharmaceutical Co., Ltd., Yichang, China) was performed. Tracheal intubation was performed to maintain anesthesia and remifentanil (Jiangsu Nhwa Pharmaceutical Co., Ltd., Xuzhou, China; approval no. H20143314) was injected at a dose of $0.1-0.2 \mu \mathrm{g} / \mathrm{kg} / \mathrm{min}$. Intravenous injection of fentanyl $(0.1 \mathrm{mg})$ was performed $5 \mathrm{~min}$ prior to the surgery. Patients in the observation group received combined epidural and general anesthesia. An epidural tube (21Gx1000; cat. no. 79.8089.150; Sarstedt, Inc., Newton, NC, USA) was placed into the T8-10 intervertebral space prior to induction of anesthesia. Lidocaine (3 ml; Jincheng Hayes Pharmaceutical Co., Ltd., Jincheng, China; approval no. H14023559) was injected. The block was confirmed to be successful when it reached T4-T12. Subsequently, general anesthesia was performed using the same method. Epidural administration of $1 \%$ lidocaine $(5-10 \mathrm{ml})$ and $0.375 \%$ ropivacaine (Guangdong Shunfeng Pharmaceutical Co., Ltd., Shunde, China; approval no. H20050325) was performed using a micropump $(5-8 \mathrm{ml} / \mathrm{h})$. After the surgery, patients in the control group were treated with intravenous analgesia by infusion of sufentanil (1 $\mu \mathrm{g} / \mathrm{ml}$; Yichang Renfu Pharmaceutical Co., Ltd.; approval no. H20054172) at a speed of $5 \mathrm{ml} / \mathrm{h}$. Patients in the observation group were subjected to epidural analgesia by injecting ropivacaine $(0.12 \%)$ and sufentanil $(0.2 \mu \mathrm{g} / \mathrm{ml})$ at a rate of $5 \mathrm{ml} / \mathrm{h}$. Post-operative analgesia was performed for 2-6 days depending on the individual condition of each patient.

Blood extraction. Venous blood $(5 \mathrm{ml})$ was extracted from each participant immediately prior to anesthesia (T1), $2 \mathrm{~h}$ after the beginning of the surgery (T2), immediately after the surgery (T3), $24 \mathrm{~h}$ after surgery (T4), $48 \mathrm{~h}$ after surgery (T5) and $72 \mathrm{~h}$ after surgery (T6).

Detection of T-lymphocyte subsets and natural killer cells. Percentages of viable $\mathrm{T}$ lymphocyte subsets, including $\mathrm{CD}^{+}$, $\mathrm{CD}^{+}$and $\mathrm{CD}^{+}$cells, were measured by flow cytometry (BD Accuri $^{\mathrm{TM}}$ C6 Plus; BD Biosciences, Franklin Lakes, NJ, USA). The $\mathrm{CD}^{+} / \mathrm{CD}^{+}$ratio was calculated.
Table I. Comparison of general characteristics between the observation and control groups.

\begin{tabular}{|c|c|c|c|}
\hline Item & $\begin{array}{l}\text { Control } \\
(n=53)\end{array}$ & $\begin{array}{l}\text { Observation } \\
\quad(n=54)\end{array}$ & P-value \\
\hline Sex & & & 0.357 \\
\hline Male & $35(66 \%)$ & 37 & \\
\hline Female & $18(34 \%)$ & 17 & \\
\hline Age (years) & & & 0.331 \\
\hline Range & $27-74$ & $30-75$ & \\
\hline Median & 47.2 & 47.5 & \\
\hline Average & $49.3 \pm 12.6$ & $48.6 \pm 11.9$ & \\
\hline BMI $\left(\mathrm{kg} / \mathrm{m}^{2}\right)$ & $20.34 \pm 1.23$ & $20.22 \pm 1.31$ & 0.323 \\
\hline Weight (kg) & $61.22 \pm 5.76$ & $63.13 \pm 7.33$ & 0.191 \\
\hline LNM (cases) & & & 0.146 \\
\hline Yes & 22 & 25 & \\
\hline No & 31 & 29 & \\
\hline
\end{tabular}

Anesthesia time $(\mathrm{min}) \quad 277.91 \pm 28.36 \quad 286.43 \pm 31.93 \quad 0.237$

Surgical time (min) $\quad 211.72 \pm 44.34 \quad 205.02 \pm 52.22 \quad 0.212$

Values are expressed as $\mathrm{n}$ and (\%) or as the mean \pm standard deviation. BMI, body mass index; LNM, lymph node metastasis.

Detection of tumor markers. Levels of carcinoembryonic antigen (CEA) in the serum were measured using CA15-3 levels determined using AN automatic electrochemistry luminescence immunoassay system (ROCHE E170; Roche Diagnostics $\mathrm{GmbH}$, Mannheim, Germany) according to the manufacturer's instructions.

Detection of inflammatory cytokines. The levels of pro-inflammatory cytokines interleukin (IL)-1, IL-8, high-sensitivity C-reactive protein (hs-CRP) and tumor necrosis factor (TNF)- $\alpha$ were measured by ELISA using human IL-1 ELISA kit (cat. no. KHC0011; Thermo Fisher Scientific, Inc., Waltham, MA, USA), IL-8 ELISA kit (cat. no. BMS204-3; Thermo Fisher Scientific, Inc.), human hs-CRP ELISA kit (cat. no. HK369; Hycult Biotech, Uden, Netherlands) and human TNF- $\alpha$ ELISA kit (cat. no. KHC3011; Thermo Fisher Scientific, Inc.) according to manufacturer's instructions.

Statistical analysis. SPSS 19.0(IBM Corp.,Armonk, NY, USA) software was used for all statistical analyses. Measurement data were expressed as the mean \pm standard deviation, and the Student's t-test was used for comparisons between the two groups. Count data were expressed as a rate and analyzed using the $\chi^{2}$ test. $\mathrm{P}<0.05$ was considered to indicate a statistically significant difference.

\section{Results}

Comparison of clinical data. The general clinical data were compared between the two groups. As presented in Table I, no significant differences in sex, mean age, average age, body 

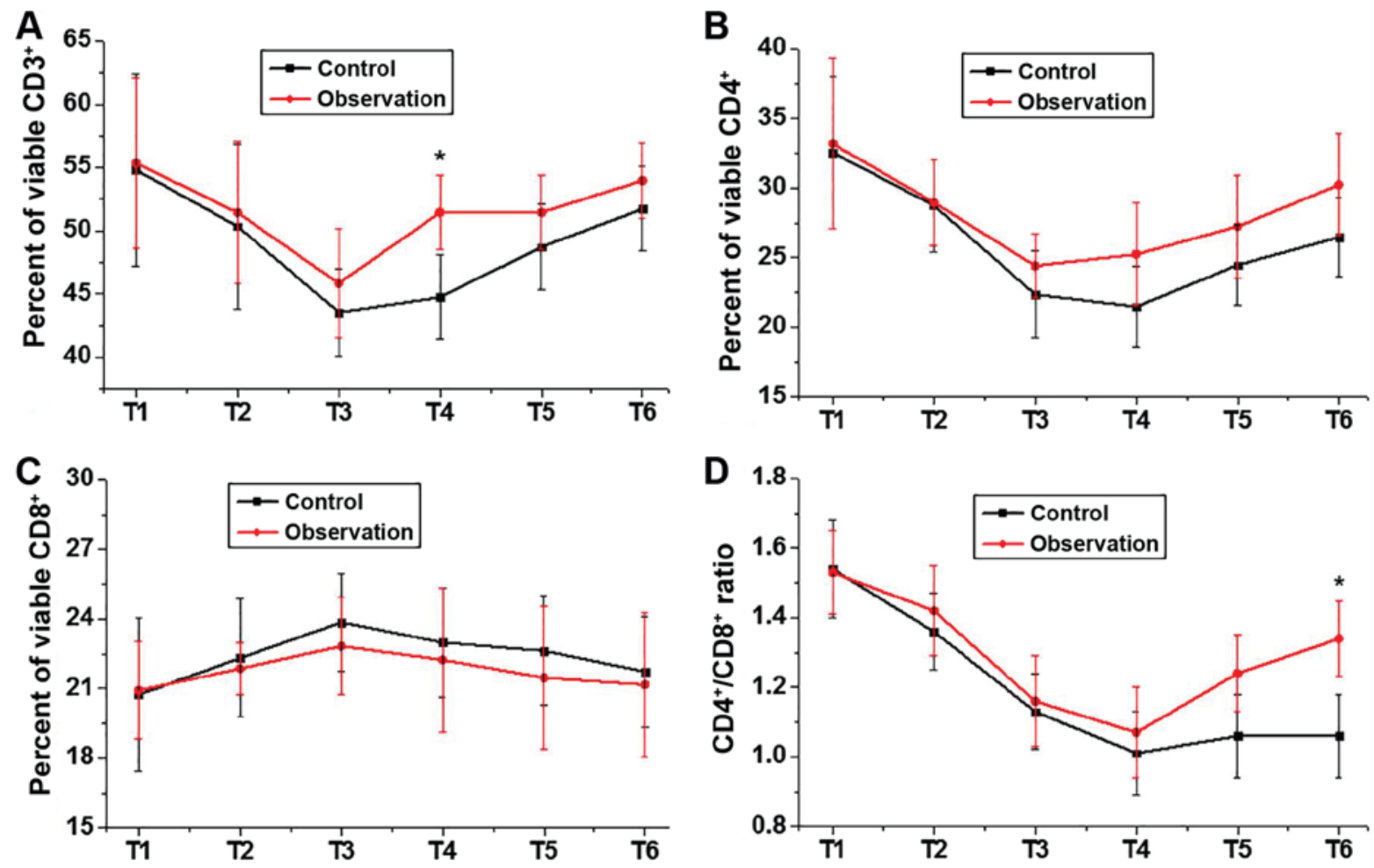

Figure 1. Comparison of the percentage of viable $\mathrm{T}$ lymphocyte subsets between the two groups at different time-points. (A-C) The percentage of viable (A) $\mathrm{CD}^{+}$, (B) $\mathrm{CD}^{+}$and (C) $\mathrm{CD}^{+} \mathrm{T}$-lymphocyte subsets and (D) the $\mathrm{CD}^{+} / \mathrm{CD}^{+}$ratio in the two groups. The percentage of $\mathrm{CD} 3^{+}$and $\mathrm{CD} 4^{+} \mathrm{T}-\mathrm{lymphocytes}$ and the $\mathrm{CD}^{+} / \mathrm{CD}^{+}$ratio were slightly higher, while the percentage of $\mathrm{CD} 8^{+}$in the observation group was slightly lower compared with those in the control group at each time-point. Significant differences were observed between two groups in percentage of viable $\mathrm{CD}^{+}$at $\mathrm{T} 4$ and in the $\mathrm{CD} 4^{+} / \mathrm{CD} 8^{+}$ratio at $\mathrm{T} 6$. Time-points: T2, immediately prior to anesthesia; T2, $2 \mathrm{~h}$ after the beginning of the surgery; T3, immediately after the surgery; T4, $24 \mathrm{~h}$ after surgery; T5, 48 $\mathrm{h}$ after surgery; $\mathrm{T} 6,72 \mathrm{~h}$ after surgery. ${ }^{*} \mathrm{P}<0.05$ vs. control group.

mass index, weight and presence of LNM were identified between the two groups $(\mathrm{P}>0.05)$. In addition, no significant differences in anesthesia time and surgical time were noted between the two groups $(\mathrm{P}>0.05)$, indicating that compared with general anesthesia, combined epidural and general anesthesia did not increase the anesthesia time and surgical time.

Comparison of percentages of viable T-lymphocyte subsets between the two groups at different time-points. The percentages of viable T-lymphocyte subsets, including $\mathrm{CD}^{+}, \mathrm{CD}^{+}$ and $\mathrm{CD} 8^{+}$cells, were measured by flow cytometry, and the $\mathrm{CD}^{+} / \mathrm{CD}^{+}$ratio was calculated. As presented in Fig. 1, no significant differences in the percentage of viable $\mathrm{CD}^{+}, \mathrm{CD}^{+}$ and $\mathrm{CD} 8^{+}$cells, or the $\mathrm{CD} 4^{+} / \mathrm{CD} 8^{+}$ratio were identified between the two groups prior to anesthesia. The percentage of $\mathrm{CD}^{+}$and $\mathrm{CD}^{+}$cells, as well as the $\mathrm{CD} 4^{+} / \mathrm{CD}^{+}$ratio, were decreased during surgery and increased after surgery in the two groups. By contrast, the percentage of $\mathrm{CD}^{+}$cells was increased during surgery and decreased after surgery. Although most differences were not statistically significant, the percentages of $\mathrm{CD}^{+}$and $\mathrm{CD}^{+}$cells and the $\mathrm{CD}^{+} / \mathrm{CD}^{+}$ratio were slightly higher, while percentage of $\mathrm{CD}^{+}$cells was slightly lower in observation group compared with that that in the control group. Significant differences were observed between two groups in percentage of viable $\mathrm{CD}^{+}$at $\mathrm{T} 4$ and in $\mathrm{CD}^{+} / \mathrm{CD}^{+}$ratio at $\mathrm{T} 6$.

Comparison of inflammatory cytokines between the two groups. ELISA was used to determine the levels of the pro-inflammatory cytokines IL-1, IL- 8 , hs-CRP and TNF- $\alpha$ at different time-points. As presented in Fig. 2, no significant differences in the serum levels of IL-1, IL-8, hs-CRP and TNF- $\alpha$ were identified between the two groups prior to anesthesia. The serum levels of IL-1, IL-8, hs-CRP and TNF- $\alpha$ were increased during the surgery and decreased after the surgery in each of the two groups. Although most differences were not statistically significant, the serum levels of IL-1, IL-8 and hs-CRP in the observation group were slightly lower than those in the control group.

Comparison of serum levels of CEA between the two groups. CEA has been widely used in the diagnosis of various types of malignancies. As presented in Fig. 3, no significant differences in the serum levels of CEA were identified between the two groups prior to anesthesia. The serum levels of CEA were slightly decreased after surgery in each of the groups. No significant differences in the serum levels of CEA were identified between the observation group and the control group. A clear decreasing trend was observed in both groups.

Comparison of adverse reactions between the two groups. The incidence of adverse reactions within 3 days after the operation was recorded and compared between the two groups. As presented in Table II, no significant differences in the incidence of hypoxemia and delayed recovery were identified between the two groups. By contrast, the incidence of nausea and vomiting, as well as post-operative agitation were 

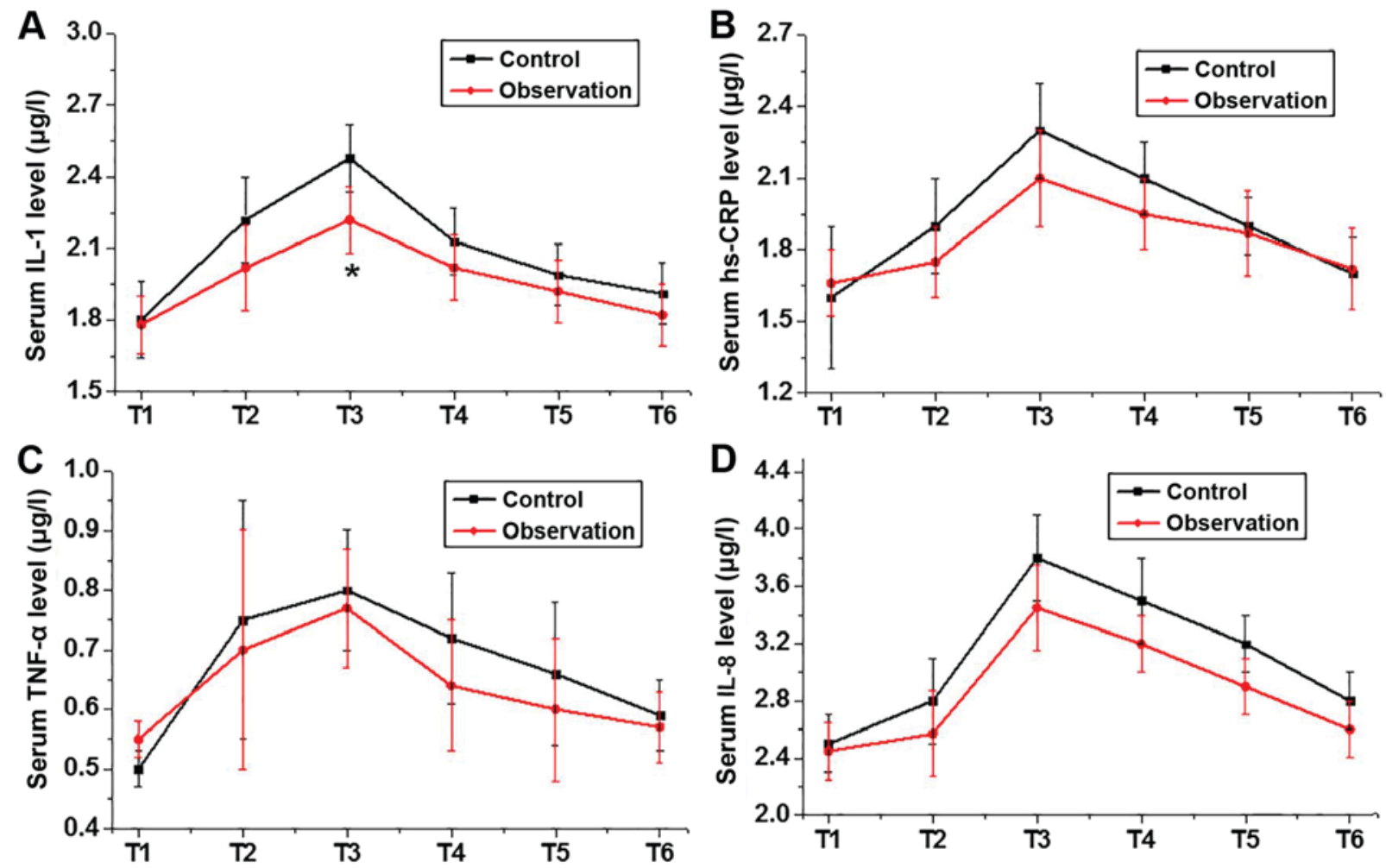

Figure 2. Comparison of inflammatory cytokines between the two groups. Serum levels of (A) IL-1, (B) hs-CRP, (C) TNF- $\alpha$ and (D) IL-8. The serum levels of IL-1, IL-8 and hs-CRP in the observation group were slightly lower than those in the control group at each time-point. Significant differences were observed between two groups in serum levels of IL-1 at T3. Time-points: T2, immediately prior to anesthesia; T2, $2 \mathrm{~h}$ after the beginning of the surgery; T3, immediately after the surgery; T4, $24 \mathrm{~h}$ after surgery; T5, $48 \mathrm{~h}$ after surgery; T6, $72 \mathrm{~h}$ after surgery. ${ }^{*} \mathrm{P}<0.05$ vs. control group. IL, interleukin; hs-CRP, high-sensitivity C-reactive protein; TNF, tumor necrosis factor.

significantly lower in the observation group than those in the control group $(\mathrm{P}<0.05)$.

\section{Discussion}

Gastric cancer is a type of malignancy that originates from the lining of the stomach and poses a serious threat to the health and life of humans (10). In recent years, the incidence of gastric cancer has exhibited an increasing trend, possibly due to changes in lifestyle and diet. At present, gastric cancer is considered to be one of the most common malignancies worldwide. In China, the incidence rate of gastric cancer ranks third among all types of malignancies in females and is only lower than that of lung cancer and breast cancer; in males it ranks second followign lung cancer (11). Men are generally more vulnerable to gastric cancer than women (12). In the present study, male patients accounted for $67.3 \%$ of all cases and only 35 patients $(32.7 \%)$ were females.

Cancer patients usually have an impaired immune function (13). During surgical preparation and operation, stress reactions caused by incisions and anesthetics, including opioids, may further inhibit immune function (14). Percentages of viable T-lymphocyte subsets are usually employed to refelect immune function. The CD3 T-cell co-receptor mediates the activation of T-helper cells (CD4 ${ }^{+}$naïve $\mathrm{T}$ cells) and cytotoxic $\mathrm{T}$ cells $\left(\mathrm{CD} 8^{+}\right.$naïve $\mathrm{T}$ cells) $(15)$. The $\mathrm{CD} 4^{+} / \mathrm{CD}^{+}$ratio in the peripheral blood of normal healthy adults is approximately 2:1, and a reduced $\mathrm{CD} 4^{+} / \mathrm{CD}^{+}$ratio indicates morbidities associated with immunodeficiency or autoimmunity (16). In

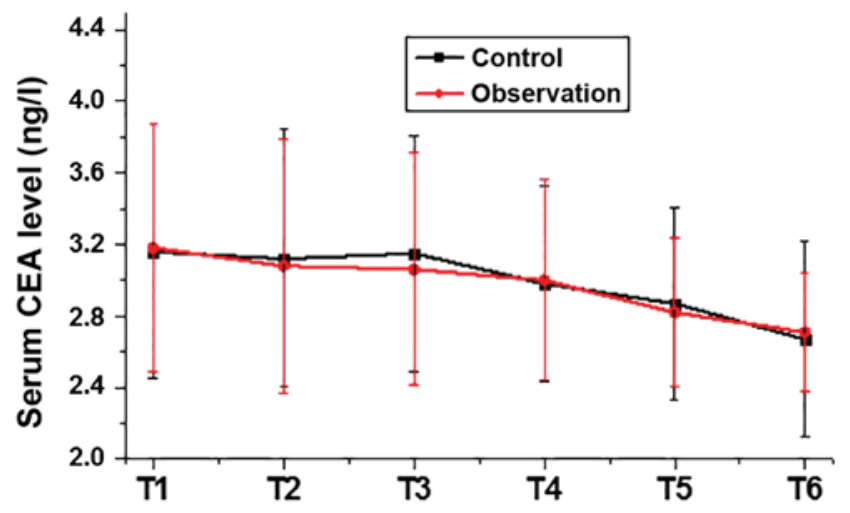

Figure 3. Comparison of serum levels of CEA between the two groups. No significant differences in the serum levels of CEA were identified between two groups. Time-points: T2, immediately prior to anesthesia; T2, $2 \mathrm{~h}$ after the beginning of the surgery; $\mathrm{T} 3$, immediately after the surgery; $\mathrm{T} 4,24 \mathrm{~h}$ after surgery; T5, $48 \mathrm{~h}$ after surgery; T6, $72 \mathrm{~h}$ after surgery. CEA, carcinoembryonic antigen.

the present study, the percentage of $\mathrm{CD}^{+}$and $\mathrm{CD} 4^{+}$cells, as well as the $\mathrm{CD}^{+} / \mathrm{CD} 8^{+}$ratio, were decreased during surgery. By contrast, the percentage of $\mathrm{CD} 8^{+}$cells was increased, which indicated a reduced immune function caused by the surgical operation and anesthetics. The possible explanation is that trauma and anesthetics may promote the secretion of catechol and adrenaline, which may inhibit T-lymphocyte immune function. After treatment, the percentage of $\mathrm{CD}^{+}$and $\mathrm{CD} 4^{+}$ cells, and the $\mathrm{CD}^{+} / \mathrm{CD}^{+}$ratio were increased, while the 
Table II. Comparison of adverse reactions between the observation and control groups.

\begin{tabular}{|c|c|c|c|c|}
\hline Adverse event & Observation $(\mathrm{n}=54)(\%)$ & Control $(\mathrm{n}=53)(\%)$ & $\chi^{2}$ & P-value \\
\hline Nausea and vomiting & $1(1.9)$ & $5(9.4)$ & 1.323 & 0.041 \\
\hline Hypoxemia & $1(1.9)$ & $3(5.7)$ & 0.277 & 0.21 \\
\hline Post-operative agitation & 0 & $6(11.3)$ & 4.427 & 0.035 \\
\hline Delayed recovery & $2(3.7)$ & $4(7.5)$ & 0.198 & 0.171 \\
\hline
\end{tabular}

Values are expressed as $\mathrm{n}(\%)$.

percentage of $\mathrm{CD}^{+}$cells was decreased. In addition, although no significant differences were identified at most time-points, the percentage of $\mathrm{CD}^{+}$and $\mathrm{CD}^{+}$, and the $\mathrm{CD}^{+} / \mathrm{CD}^{+}$ratio in observation group were higher, while the percentage of $\mathrm{CD}^{+}$was lower than that in control group. This is due to the fact that the cerebral cortex limbic system may be inhibited by general anesthesia, so that central conduction is nociceptively stimulated, leading to an obvious stress response and a reduced cellular immune function (17). By contrast, epidural anesthesia has no significant effects on the sensitivity of the immune response. Therefore, nerve impulses caused by traumatic stimulation may be effectively inhibited.

Stress responses mediated by anesthesia may lead to changes in the synthesis and secretion of catechins, which in turn stimulate the secretion of inflammatory cytokines and cause inflammatory reactions (18). IL- 1 and IL- 8 are two pro-inflammatory factors involved in the development of vairous human diseases (19). As a major acute-phase reactant, levels of CRP reflect the severity of the inflammatory response (20). As another pro-inflammatory factor, the levels of TNF- $\alpha$ reflect the severity of the inflammatory response and immune function (21). In the present study, the serum levels of IL-1, IL-8, hs-CRP and TNF- $\alpha$ were increased during the surgery, which indicated the presence of an inflammatory reponse caused by surigical trauma and anesthetics. After the sugery, the serum levels of IL-1, IL-8, hs-CRP and TNF- $\alpha$ were decreased again. Although no significant differences were observed in most cases, the serum levels of IL-1, IL-8 and hs-CRP in the observation group were lower than those in the control group. These results suggest that compared with general anesthesia, combined epidural and general anesthesia inhibits the inflammatory response. This may possibly be explained by the reduced stress response and less adverse effects of epidural anesthesia on the entire body. However, it's known that particular levels of inflammatory reposes promote wounding healing (22). Therefore, the fine regulation of surgical inflammation remains to be further investigated and discussed.

Serum CEA has been widely used to predict the recurrence of gastric cancer after treatment, and high levels of serum CEA indicate a high risk of post-operative recurrence (23). In the present study, no significant differences were identified in the serum levels of CEA between the observation group and the control group at different time-points after surgery, indicating that combined epidural and general anesthesia is not superior to general anesthesia in inhibiting post-operative recurrence of gastric cancer. However, compared with patients treated with general anesthesia, combined epidural and general anesthesia significantly inhibited the occurrence of nausea and vomiting, as well as post-operative agitation, although no significant differences in the incidence of hypoxemia and delayed recovery were identified between the two groups. Therefore, future studies by our group will focus on the reduction of the incidence of hypoxemia and delayed recovery. The present study did not include the analysis of post-operative analgesia. Patients in the control group were treated with intravenous analgesia by infusion of sufentanil for post-operative analgesia, while patients in the observation group received ropivacaine combined with sufentanil at a lower dose. The different types of post-operative analgesia may affect inflammation in patients. Further study will investigate the effects of post-operative analgesia modes on inflammatory responses.

In conclusion, compared with general anesthesia, combined epidural and general anesthesia inhibits the inflammatory response, improves immune function and inhibits the occurrence of certain post-operative adverse events in patients with EGC that underwent tumor resection.

\section{Acknowledgements}

Not applicable.

\section{Funding}

No funding was received.

\section{Availability of data and materials}

The datasets used and/or analyzed during the current study are available from the corresponding author on reasonable request.

\section{Authors' contributions}

LZ designed the experiments. WL and LW performed experiments. MZ analyzed the data. LZ drafted the manuscript. The final version of the manuscript has been read and approved by all authors, and each author believes that the manuscript represents honest work.

\section{Ethics approval and consent to participate}

The Ethics Committee of General Hospital of Daqing Oil Field of Heilongjiang approved the present study and all patients provided written informed consent. 


\section{Patient consent for publication}

Not applicable.

\section{Competing interests}

The authors declare that they have no competing interests.

\section{References}

1. Yasunaga H, Horiguchi H, Kuwabara K, Matsuda S, Fushimi K, Hashimoto $\mathrm{H}$ and Ayanian JZ: Outcomes after laparoscopic or open distal gastrectomy for early-stage gastric cancer: A propensity-matched analysis. Ann Surg 257: 640-646, 2013.

2. Choi WJ, Baek S, Joo EY, Yoon SH, Kim E, Hong B, Hwang JH and Kim YK: Comparison of the effect of spinal anesthesia and general anesthesia on 5-year tumor recurrence rates after transurethral resection of bladder tumors. Oncotarget 8: 87667-87674, 2017.

3. Mahle WT, Matthews E, Kanter KR, Kogon BE, Hamrick SE and Strickland MJ: Inflammatory response after neonatal cardiac surgery and its relationship to clinical outcomes. Ann Thorac Surg 97: 950-956, 2014.

4. Martelli D, Yao ST, Mancera J, McKinley MJ and McAllen RM: Reflex control of inflammation by the splanchnic anti-inflammatory pathway is sustained and independent of anesthesia. Am J Physiol Regul Integr Comp Physiol 307: R1085-R1091, 2014.

5. Thomas SN, Vokali E, Lund AW, Hubbell JA and Swartz MA: Targeting the tumor-draining lymph node with adjuvanted nanoparticles reshapes the anti-tumor immune response. Biomaterials 35: 814-824, 2014.

6. Cheng YC, Cheng XB, Li XJ, Wang FZ and Li ZK: Combined general and regional anesthesia and effects on immune function in patients with benign ovarian tumors treated by laparoscopic therapy. Int J Clin Exp Med 6: 716-719, 2013.

7. Zhang T, Fan Y, Liu K and Wang Y: Effects of different general anaesthetic techniques on immune responses in patients undergoing surgery for tongue cancer. Anaesth Intensive Care 42: 220-227, 2014

8. Japanese Gastric Cancer Association: Japanese classification of gastric carcinoma-2nd english edition. Gastric Cancer 1: 10-24, 1998.

9. Abe N, Mori T, Takeuchi H, Yoshida T, Ohki A, Ueki H, Yanagida O, Masaki T, Sugiyama M and Atomi Y: Laparoscopic lymph node dissection after endoscopic submucosal dissection: A novel and minimally invasive approach to treating early-stage gastric cancer. Am J Surg 190: 496-503, 2005.

10. Karimi P, Islami F, Anandasabapathy S, Freedman ND and Kamangar F: Gastric cancer: Descriptive epidemiology, risk factors, screening and prevention. Cancer Epidemiol Biomarkers Prev 23: 700-713, 2014

11. Chen W, Zheng R, Zhang S, Zhao P, Zeng H, Zou X and He J: Annual report on status of cancer in China, 2010. Chin J Cancer Res 26: 48-58, 2014
12. Rugge M, Fassan M and Graham DY: Epidemiology of gastric cancer. Springer International Publishing Switzerland. Gastric Cancer: 23-34, 2015.

13. Brandacher G, Winkler C, Schroecksnadel K, Margreiter R and Fuchs D: Antitumoral activity of interferon-gamma involved in impaired immune function in cancer patients. Curr Drug Metab 7: 599-612, 2006

14. Sprung J, Scavonetto F, Yeoh TY, Kramer JM, Karnes RJ, Eisenach JH, Schroeder DR and Weingarten TN: Outcomes after radical prostatectomy for cancer: A comparison between general anesthesia and epidural anesthesia with fentanyl analgesia: A matched cohort study. Anesth Analg 119: 859-866, 2014.

15. Birnbaum ME, Berry R, Hsiao YS, Chen Z, Shingu-Vazquez MA, Yu X, Waghray D, Fischer S, McCluskey J, Rossjohn J, et al: Molecular architecture of the $\alpha \beta \mathrm{T}$ cell receptor-CD3 complex. Proc Natl Acad Sci USA 111: 17576-17581, 2014.

16. Luz Correa B, Ornaghi AP, Cerutti Muller G, Engroff P, Pestana Lopes R, Gomes da Silva Filho I, Bosch JA, Bonorino C and Bauer ME: The inverted CD4:CD8 ratio is associated with cytomegalovirus, poor cognitive and functional states in older adults. Neuroimmunomodulation 21: 206-212, 2014.

17. Hung MH, Chan KC, Liu YJ, Hsu HH, Chen KC, Cheng YJ and Chen JS: Nonintubated thoracoscopic lobectomy for lung cancer using epidural anesthesia and intercostal blockade: A retrospective cohort study of 238 cases. Medicine (Baltimore) 94: e727, 2015.

18. Li B, Li Y, Tian S, Wang HX, Wu H, Zhang A and Gao C: Anti-inflammatory effects of perioperative dexmedetomidine administered as an adjunct to general anesthesia: A meta-analysis. Sci Rep 5: 12342, 2015.

19. Dinarello CA: The IL-1 family and inflammatory diseases. Clin Exp Rheumatol 20 (Suppl 27): S1-S13, 2002.

20. Karadeniz M, Duran M, Akyel A, Yarlıoğlues M, Öcek AH, Çelik İE, Kılıç A, Yalcin AA, Ergün G and Murat SN: High sensitive CRP level is associated with intermediate and high syntax score in patients with acute coronary syndrome. Int Heart J 56: 377-380, 2015.

21. Murdaca G, Spanò F, Contatore M, Guastalla A, Penza E, Magnani $O$ and Puppo F: Infection risk associated with anti-TNF- $\alpha$ agents: A review. Expert Opin Drug Saf 14: 571-582, 2015.

22. Hunt TK, Knighton DR, Thakral KK, Goodson WH III and Andrews WS: Studies on inflammation and wound healing: Angiogenesis and collagen synthesis stimulated in vivo by resident and activated wound macrophages. Surgery 96: 48-54, 1984.

23. Takahashi Y, Takeuchi T, Sakamoto J, Touge T, Mai M, Ohkura H, Kodaira S, Okajima K and Nakazato H; Tumor Marker Committee: The usefulness of CEA and/or CA19-9 in monitoring for recurrence in gastric cancer patients: A prospective clinical study. Gastric Cancer 6: 142-145, 2003.

This work is licensed under a Creative Commons Attribution-NonCommercial-NoDerivatives 4.0 International (CC BY-NC-ND 4.0) License. 